\title{
Racecadotril Efficacy in the Symptomatic Treatment of Adult Acute Diarrhoea: A Systematic Review and Meta-Analysis
}

\author{
Jean-Marie Vetel ${ }^{1}$, Habib Hamza ${ }^{2}$, Benoît Coffin ${ }^{3}$, Philippe Lehert ${ }^{4,5 *}$ \\ ${ }^{1}$ Geriatric Department, Centre Hospitalier du Mans, Le Mans, France \\ ${ }^{2}$ Clinique Taoufik, Tunis, Tunisia \\ ${ }^{3}$ Hepatogastroenterology Department, Louis-Mourier Hospital, Colombes, France \\ ${ }^{4}$ Faculty of Economics, UCL Mons, Louvain, Belgium \\ ${ }^{5}$ Faculty of Medicine, The University of Melbourne, Melbourne, Australia \\ Email: geriatrjm@yahoo.fr, fatma hamza97@hotmail.fr, benoit.coffin@lmr.aphp.fr, \\ lehertphilippe@gmail.com
}

Received 27 January 2014; revised 25 February 2014; accepted 24 March 2014

Copyright (C) 2014 by authors and Scientific Research Publishing Inc.

This work is licensed under the Creative Commons Attribution International License (CC BY). http://creativecommons.org/licenses/by/4.0/

\section{Open Access}

\section{Abstract}

The efficacy of racecadotril (RC), an intestinal antisecretory drug acting via an enkephalinase inhibition, was reviewed in paediatric acute diarrhoea but not yet in adults. Objective: To estimate the effectiveness of RC in the symptomatic treatment of acute diarrhoea in adults. Data Sources: A systematic review of MedLine, Cochrane Controlled Trials Register, DARE, and Embase (up to November 2013). Additional studies were identified by contacting clinical experts and the manufacturer. Study Selection and Appraisal: Randomized Controlled Trials performed in adults suffering from acute diarrhoea using RC in one treatment arm. Independent extraction of articles using predefined data fields, and methodological quality measurement assessment. All randomised trials performed in adults suffering from acute diarrhoea with RC as the studied group. Statistics: The main efficacy endpoint was diarrhoea duration defined as time to recovery compared between groups by survival techniques and converted into hazard ratio (HR). We exclusively used a random-effect meta-analytic model. Constipation proportion was the main safety endpoint, evaluated between treatments by the Relative Risks (RR). Results: Twelve randomised trials (2619 patients) met inclusion criteria. Duration of diarrhoea was much shorter in the RC group, the proportion of patients having recovered at any time of the treatment period was $65 \%$ higher in the RC group, compared with placebo $(\mathrm{HR}=1.65[1.38-1.97], p<0.00001, \mathrm{n}=1001)$. Duration of diarrhoea was similar in the $R C$ and loperamide groups $(H R=1.08[0.95-1.22], p=0.24, n=1618)$. The proportions of constipated patients were similar in the RC and placebo groups 0.95 [0.24 3.68], $p=0.97$ ), however, about 3 times more constipated patients were found in the loperamide group compared with the RC group $(R R=0.34[0.22-0.51], p<0.0001)$. Conclusions: Compared

\footnotetext{
${ }^{*}$ Corresponding author.
} 
to placebo, RC is characterized by a clinically relevant earlier remission of diarrhoea. When compared to loperamide, diarrhoea duration was similar, however, significantly fewer secondary constipation adverse effects were observed.

\section{Keywords}

\section{Acute Diarrhoea, Meta-Analysis, Racecadotril}

\section{Introduction}

\subsection{Rationale}

Acute diarrhoea is a source of plenty common ideas, such as paediatrics is the only matter of concern, it is a self-limited condition that does not need medical intervention and if the patients wish a symptomatic treatment, an OTC agent will be sufficient. For the first point, the mortality induced by acute diarrhoea does occur mainly in infants, especially in the developing world. But in the developed countries, the mortality in adults, especially in elderly, is underestimated because it occurs after a delay due to visceral failure secondary to dehydration [1] Almost acute gastroenteritis resolve spontaneously within a miscellaneous period of time, depending of epidemiological conditions. In this active population, shortening the period of incapacity can be a major concern because it induces a huge cost [2].

There is a need for a drug, with a safe profile, that means, in particular, devoid of antimotility action, and with an established efficacy in order to reduce the diarrhoea duration.

Racecadotril is an antidiarrhoeal drug whose safety is well established, both in paediatrics [3] and in adults [4]. It acts via an enkephalinase inhibition, thus it reinforces the intestinal antisecretory effect of enkephalins [5] and has no antimotility effect [6]. Its efficacy has been recently reviewed in an individual patient data meta-analysis in paediatrics [7]. But a review of its efficacy in an adult population is still lacking.

\subsection{Objectives}

To examine whether RC reduces diarrhoea duration, we reviewed randomized, controlled trials that assessed the efficacy of this drug for the symptomatic treatment of acute diarrhoea compared to any comparator in adults.

\section{Methods}

\subsection{Eligibility Criteria}

Participants above 18 years old, male or female, with acute diarrhoea (AD) were considered, whatever the presumed cause of AD except cholera, healthy volunteers, paediatric patients, patients with chronic HIV-related diarrhoea, or due to anticancerous chemotherapy. The intervention was RC, adult formulation, without dosage restriction. Comparators were any control group admitted, placebo or any antidiarrhoeal drug except another formulation of RC. Outcomes were diarrhoea duration (DD) from treatment onset to the last unformed stools, and safety, in particular treatment related constipation adverse effect. Study design: all randomized controlled trials (RCT), either double-blind or single blind studies. Reports were any published data, without any restriction of language, year of publication, abstract as well as full publication.

\subsection{Information Sources, Key Words}

Studies were identified by searching electronic databases (up to November 2013): Medline (via PubMed and Ovid), Embase, ClinicalTrials.gov, Cochrane and DARE (Database of Abstracts of Reviews of Effectiveness). Besides, we contacting the authors of each identified study and questioned the manufacturer (Bioprojet Pharma), in particular on possibilities of unpublished studies. We used the following search terms to search all trials registers and databases: ("acetorphan OR racecadotril") and "Acute diarrh*” with the following limits: Humans, Clinical Trial, Adult.

\subsection{Study Selection}

Eligibility assessment was performed independently by 2 reviewers (JV, PL). Disagreements between reviewers 
were resolved by consensus. To assess the methodological quality of RCTs, a qualitative checklist for each trial was completed and independently evaluated by each reviewer [8]. The checklist comprised seven items assessing internal validity, five items of external validity, and five items of statistical validity (see Addendum A.2. Methodological Quality Questionnaire).

\subsection{Data Collection Process}

For each selected trial, a pre-defined list of items was extracted (Addendum A1) by one review author [JV] and checked by another [PL]. Disagreements were resolved by discussion between the two review authors; if no agreement could be reached, consensus was reached by vote on all the authors. If needed, study authors were contacted for clarification.

\subsection{Assessment of Risk of Bias in Individual Studies}

The methodological quality of the studies was assessed using a domain-based evaluation of three domains: internal, external, and statistical validity. We assessed the internal validity of generation of random allocation sequence, concealment of the allocation sequence, blinding of participants, health care providers, data collectors, and outcome adjudicators, proportion of patients lost to follow-up; stopping of trials early for benefit, and whether the analysis followed the intention-to-treat principle. An overall Methodological Quality Score was derived from the summary table through a principal components analysis (see Addendum A3. Construction and calculation of the Methodological Quality Index).

\subsection{Statistical Analysis}

The main endpoint was diarrhoea duration (DD) and was compared between treatment groups within each study by the Hazard Ratio HR. Frequency of constipation was defined according to study authors, whatever their own criteria.

We pooled treatment effects and calculated a weighted average risk ratio for all outcomes in the treatment and control groups by using a random-effects model [9]. We tested for between study heterogeneity in calculating the percentage of total variation across studies due to heterogeneity $\mathrm{I}^{2}$ [11] [12].

The main endpoint was expected to be reported on various ways necessitating indirect calculation for estimating the Hazard Ratios: If Cox proportional Hazard was used, results are provided in terms of HR or Log(HR). Median values were converted into HR by assuming exponential models, similarly an approximation of conversion between Log rank value and HR was used. Finally, the approximation of Var(HR) was made possible through of exponential distribution (Addendum A5). 95\% confidence intervals are uniformly reported. The statistical analysis was performed with help of R statistical package (version 2.10.1).

The risk of bias across studies was studied by the following analyses: The publication bias was tested by means of funnel plots [10], funnel plot regression [13]. Year of publication was considered as a predictor in a meta-regression model to examine a possible time-lag bias [14]. The significance of the observed difference of treatment between sponsored and non-sponsored trials was assessed. We also tested the same difference between published and non published trials. We assessed the sensitivity of our results in regressing the results according to the Methodological quality index.

\section{Results}

\subsection{Study Selection}

Overall, 28 studies were identified through database searching and 4 additional studies were found from authors and Pharma sources (Bioprojet Pharma and Smith and Beecham international). The excluded studies were: duplicate or translation of previous published trials [15], and review or meta-analysis [16]-[18], studies performed in infants or in children, in patients suffering from cholera [19], from HIV-related chronic diarrhoea [20] [21] or from subacute or recurrent diarrhoea induced by anticancerous chemotherapy [22]-[26] studies comparing 100 mg capsules RC to domestic Chinese $100 \mathrm{mg} \mathrm{RC} \mathrm{[27],} \mathrm{to} \mathrm{the} \mathrm{RC} \mathrm{isomer,} \mathrm{dexecadotril} \mathrm{[28],} \mathrm{and} \mathrm{to} 175 \mathrm{mg}$ tablets RC [29]-[31], due to the lack of a third comparator.

Further to these exclusions (see Table 1), 15 studies were included in qualitative synthesis. Two studies [32] 
Table 1. Excluded studies.

\begin{tabular}{ccll}
\hline Study & Year & Country & \multicolumn{1}{c}{ Reason for exclusion } \\
\hline Alam NH [19] & 2003 & Bangladesh & Diarrhoea due to cholera \\
Ang ER [16] & 2009 & Philippines & Meta-analysis \\
Baldi F [17] & 2009 & Italy & Review \\
Baumer P [21] & 1995 & France & Chronic HIV-related diarrhoea \\
Beaugerie L [20] & 1996 & France & Diarrhoea due to AIDS \\
Bouhnik Y [30] & 2008 & France & Comparator = racecadotril 175* \\
Coffin B [29] & 2008 & France & Comparator = racecadotril 175* \\
Coffin B [31] & 2008 & France & Comparator = racecadotril 175* \\
Dorval ED [22] & 1995 & France & Diarrhoea due to chemotherapy \\
Frexinos J [32] & 1996 & France & Abstract with low methodological score \\
Freyer G [24] & 2000 & France & Diarrhoea due to Chemotherapy \\
Eberlin M [17] & 2012 & Germany & Review \\
Gendre JP [28] & 1996 & France & Comparator = dexecadotril* \\
Goncalves E [23] & 1995 & France & Anticancerous chemotherapy \\
Lin Sanren (SB011) [27] & 2001 & China & Comparator was other RC formulation \\
Mehta S [34] & 2012 & India & Open study - no duration data \\
Saliba F [26] & 1998 & France & Anticancerous chemotherapy \\
Yao P [33] & 2011 & China & Abstract with low methodological score \\
Ychou M [25] & 2000 & France & Anticancerous chemotherapy \\
\hline & & & \\
\hline & & & \\
\hline & & &
\end{tabular}

[33] were published only as short abstracts and were characterized by low methodological scores (see Addendum A4. Individual results of the methodology quality questionnaire (recoded results). At last, a third study [34] has no data at all on DD. These last three studies were excluded from the quantitative synthesis. In final, 12 studies were included in the quantitative analysis (see Table 2).

\subsection{Study Characteristics}

The selected trials included a total of 2717 adults (intention to treat population): 1422 were assigned to RC and 1295 to control, the per protocol population was 2619 (1378 in RC groups and 1241 in control groups). Five studies were considered as placebo-controlled, four with a placebo arm [35] [36], Vetel \& Coffin: personal data], one with a Saccharomyces boulardii arm [37] and seven were loperamide-controlled [35] [39]-[42], [Lin Sanren \& Coulden: personal data]. Control group, design and population for each study are listed in Table 2.

\subsection{Synthesis of Results}

DD was first compared between RC and Placebo (Figure 1(a)) on the basis of 5 RCTS ( $\mathrm{n}=1001)$ : 65\% more patients were observed to recover in the RC group compared with placebo (Hazard Ratio HR $=1.65$ [1.38 1.97], $p<0.00001$. This result was found reasonable homogeneous between study $\left(\mathrm{I}^{2}=27 \%\right.$, heterogeneity test $\mathrm{Q}=5.48, p=0.24$ ).

In as second step, DD was compared between RC and loperamide (Figure 1(b)) on the basis of 7 RCTs ( $\mathrm{n}=$ 1618). A slightly higher but non significant proportion of recovered patients was found in RC group (HR = 1.08 [0.95 - 1.22], $p=0.24)$, this result found homogeneous between studies $\left(\mathrm{I}^{2}=0\right.$, Q test $\left.=5.48, p=0.55\right)$.

Post-treatment constipation constituted our main safety endpoint. The proportion of constipation was found 
Table 2. Included studies.

\begin{tabular}{|c|c|c|c|c|c|c|c|c|}
\hline \multirow{2}{*}{ Author } & \multirow{2}{*}{ Control group } & \multirow{2}{*}{ Design } & \multicolumn{3}{|c|}{ ITT sample size } & \multicolumn{3}{|c|}{ PP sample size } \\
\hline & & & $\mathrm{RC}$ & Control & Total & $\mathrm{RC}$ & Control & Total \\
\hline Baumer P [35] & Placebo & DB & 96 & 102 & 198 & 96 & 102 & 198 \\
\hline Hamza H [36] & Placebo & DB & 32 & 39 & 71 & 32 & 38 & 71 \\
\hline Vetel JM (multidose) & Placebo & DB & 173 & 54 & 112 & 173 & 54 & 112 \\
\hline Moraes E [36] & $S b$ & SB & 207 & 197 & 404 & 175 & 161 & 404 \\
\hline Coffin B \& Rampal P* & Placebo & DB & 86 & 87 & 173 & 83 & 87 & 173 \\
\hline Rogé J [38] & Loperamide & DB & 40 & 36 & 76 & 37 & 32 & 76 \\
\hline Vetel JM [39] & Loperamide & DB & 82 & 75 & 157 & 77 & 70 & 157 \\
\hline Prado D [40] & Loperamide & SB & 473 & 472 & 945 & 473 & 471 & 945 \\
\hline Coulden S* & Loperamide & SB & 60 & 60 & 120 & 60 & 60 & 120 \\
\hline Lin Sanren SB006* & Loperamide & SB & 112 & 111 & 223 & 111 & 104 & 223 \\
\hline Wang HH [41] & Loperamide & SB & 31 & 31 & 62 & 31 & 31 & 62 \\
\hline Gallelli L [42] & Loperamide & DB & 30 & 31 & 61 & 30 & 31 & 61 \\
\hline \multicolumn{3}{|c|}{ All studies versus placebo $(\mathrm{n}=5)$} & 594 & 479 & 1073 & 559 & 442 & 1001 \\
\hline \multicolumn{3}{|c|}{ All studies versus loperamide $(\mathrm{n}=7$ ) } & 828 & 816 & 1644 & 819 & 799 & 1618 \\
\hline \multicolumn{3}{|l|}{ All studies $(\mathrm{n}=12)$} & 1422 & 1295 & 2717 & 1378 & 1241 & 2619 \\
\hline
\end{tabular}

$\mathrm{RC}=$ racecadotril; $\mathrm{S} b=$ Saccharomyces boulardii; $\mathrm{DB}=$ double-blind; $\mathrm{SB}=$ single-blind. ${ }^{*}$ None publication (even as abstract), but available data from author/sponsor: Vetel $\mathrm{JM}=$ P.90 - 08 study (multidose) performed in France, clinical report from Bioprojet (1991): patients treated with $30 \mathrm{mg}(\mathrm{n}=59), 100 \mathrm{mg}(\mathrm{n}=58)$ or $300 \mathrm{mg}(\mathrm{n}=56)$ racecadotril; Coulden $\mathrm{S}=$ SB004 study performed in India, Clinical report by Coulden S (SBi, 2001); Lin Sanren = SB006 study performed in China, Clinical report by Hue R \& Sun $\mathrm{J}$ (SBi, 2003); Coffin B \& Rampal P = P.05-04 study performed in France, Clinical report from Bioprojet (2007).

similar between RC and Placebo (Figure 1(a)), RR = 0.95 [0.24 - 3.68], $p=0.97$ ), however, a significantly lower proportion was observed in the RC group compared with loperamide (Figure 2(b)), RR $=0.34[0.22$ $0.51, p<0.0001)$, these two results found reasonably homogeneous between studies $\left(\mathrm{I}^{2}=10 \%\right.$ and $30 \%$, respectively, Q test, $p>0.5)$.

\subsection{Risk of Bias across Studies}

Through a Funnel plot (Figure 3), we failed to identify a publication bias on the main efficacy endpoint, or in the safety endpoints (both for study comparing loperamide or placebo). For the four meta-analyses, we conducted separate meta-regression on Year of publication, Sponsored versus non-sponsored trials, and Published versus non published trials. For all these analyses, no significant effect of any of these regressors was found.

\section{Discussion}

\subsection{Summary of Evidence}

\subsubsection{Discussion on DD Definition and Its Clinical Relevance}

Definition of DD can be a matter of questions. A duration is a time interval between a startpoint and an endpoint. In all the studies, the DD startpoint was when the first therapeutic dose is taken instead of the beginning of the $\mathrm{AD}$, in order to answer to a practical question: is it worthwhile to prescribe a drug while a patient visit, whatever the AD starts. The common DD endpoint definition was when the last unformed stool is recorded, that means followed by 12 hours with no stools or two consecutive normal stools. The first formed stools can not be choosen as a recovery definition because it can be preceded by a time without any stool. The relevance of DD reduction as to be expressed not only stastistically but clinically too. As compared to placebo, no-one can affirm the minimal relevant difference of DD reduction in term on a number of hours, especially because DD may varies within placebo groups according to epidemiological conditions. Overall, RC induced a 65\% reduction of DD: 


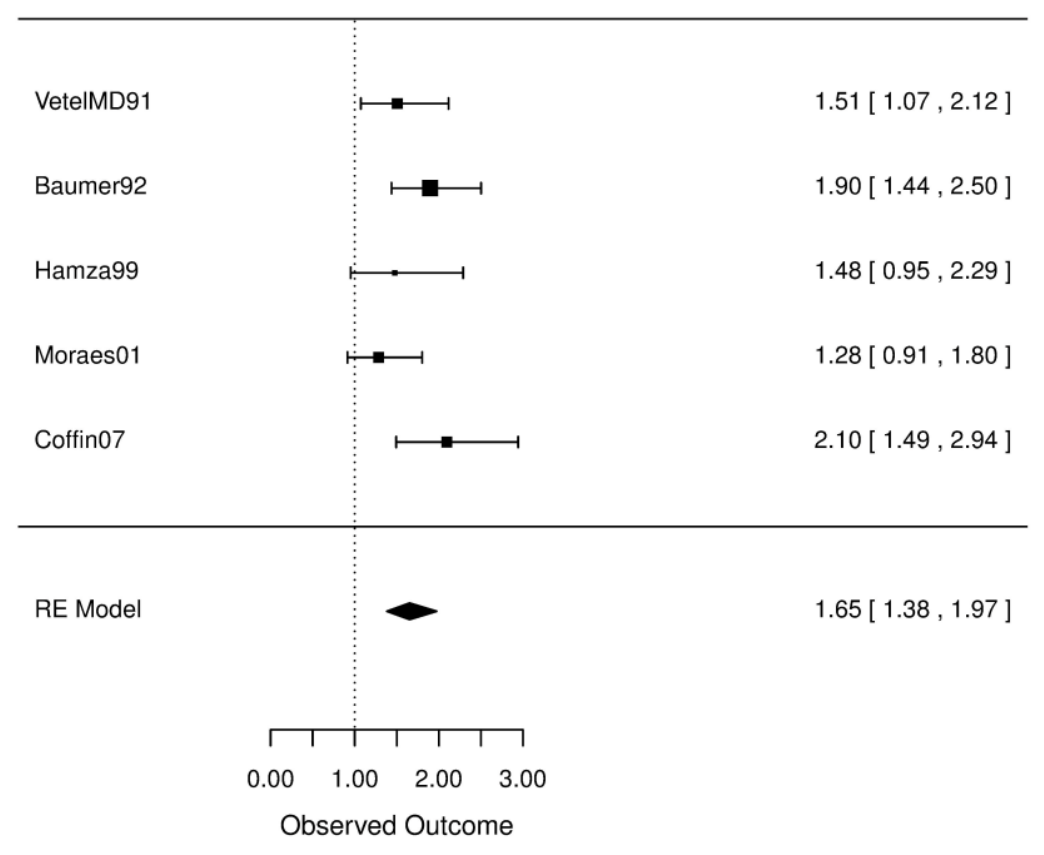

(a)

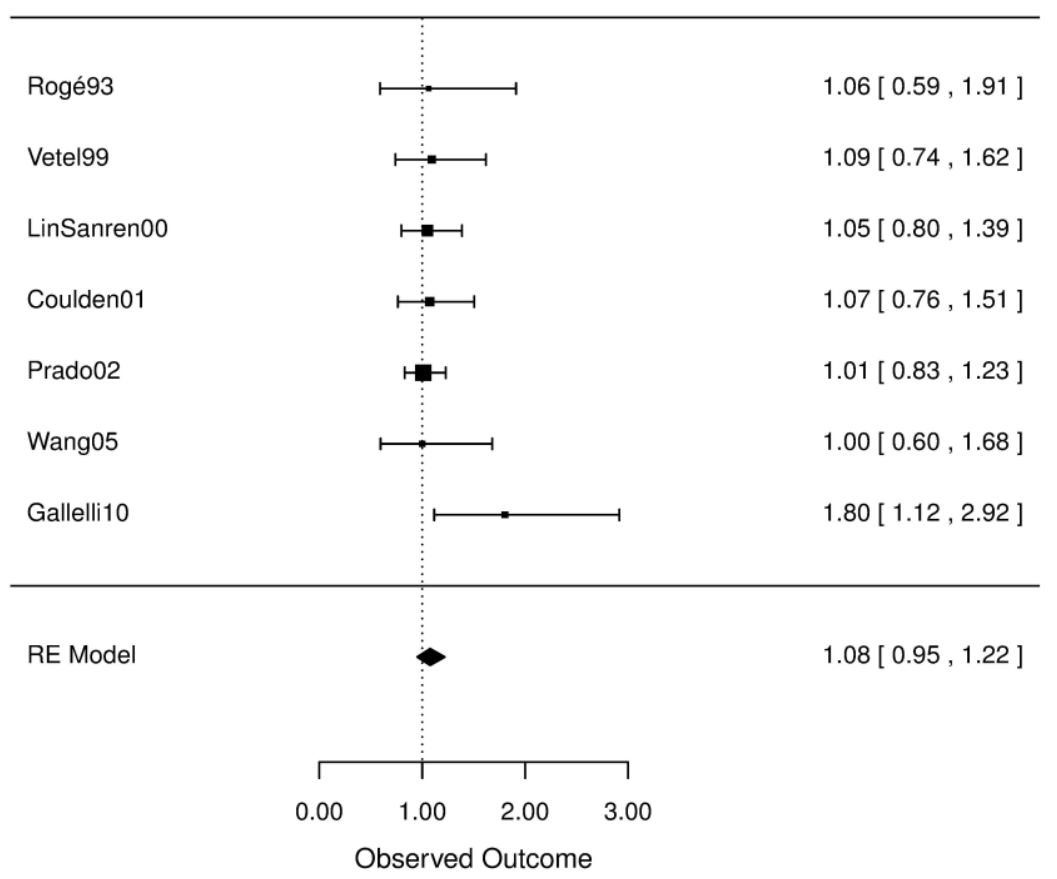

(b)

Figure 1. Diarrhoea Duration Forest Plot. Comparing Racecadotril (RC) versus placebo (on the left 1(a)) and RC versus Loperamide (on the right 1(b)), using Randomized Der Simonian and Laird Model, Risk Ratio.

this is available whatever these epidemiological conditions.

\subsubsection{Discussion on Different Antitransit Effects}

During the clinical development of loperamide, its activity was demonstrated by its constipation effect in normal volunteers: $4 \mathrm{mg}$ single dose or $3 \mathrm{mg}$ b.i.d for 5 days of loperamide were significantly superior to placebo in in- 
$k(\mathrm{rc}) \quad n(\mathrm{rc}) \quad k(\mathrm{pl}) \quad n(\mathrm{pl})$

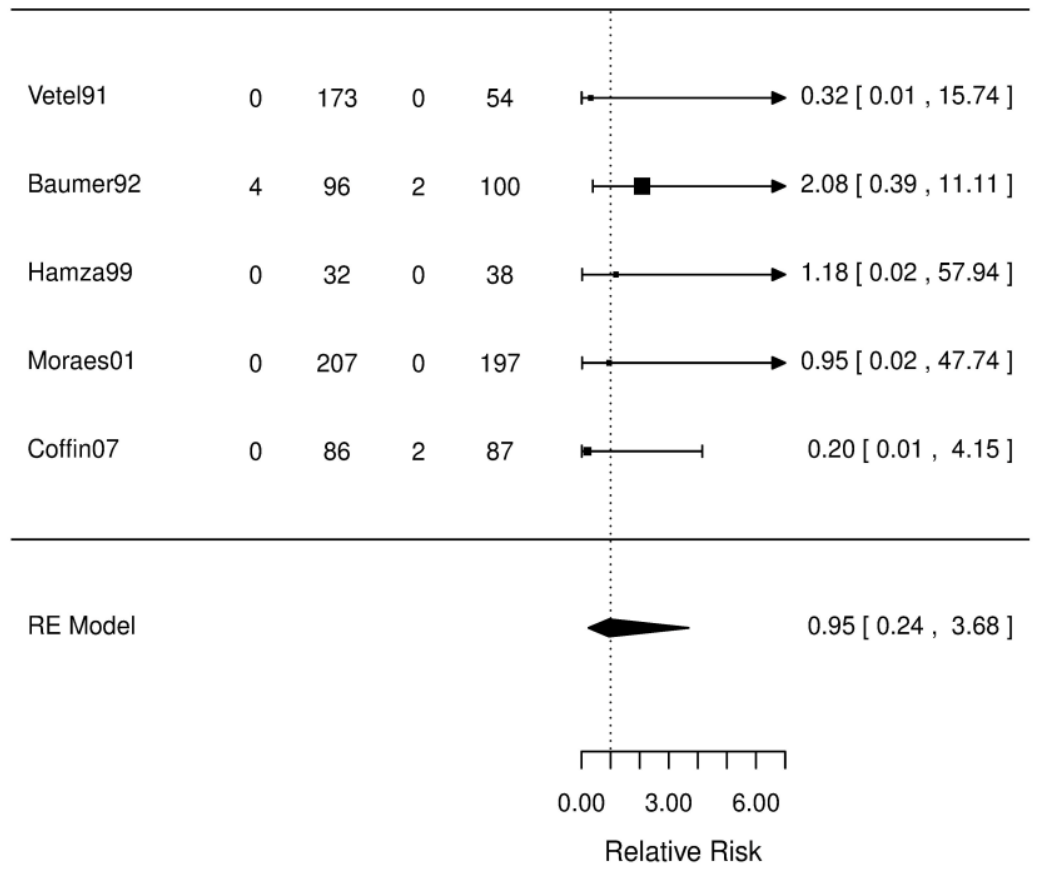

(a)

$k(r c) \quad n(r c) \quad k(l p) \quad n(l p)$

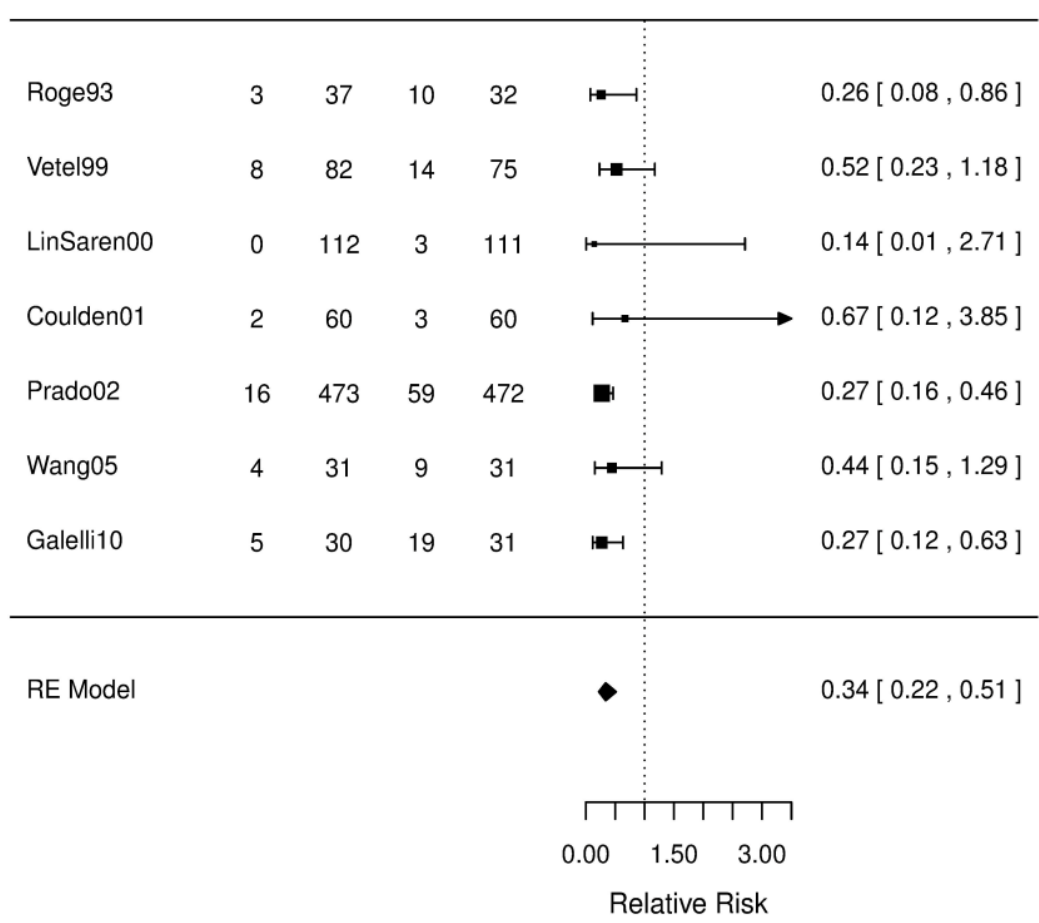

(b)

Figure 2. Constipation occurences Forest Plot. Comparing Racecadotril (RC) versus placebo (on the left 2(a)) and RC versus Loperamide (on the right 2(b)), using Randomized Der Simonian and Laird Model, Risk Ratio. 


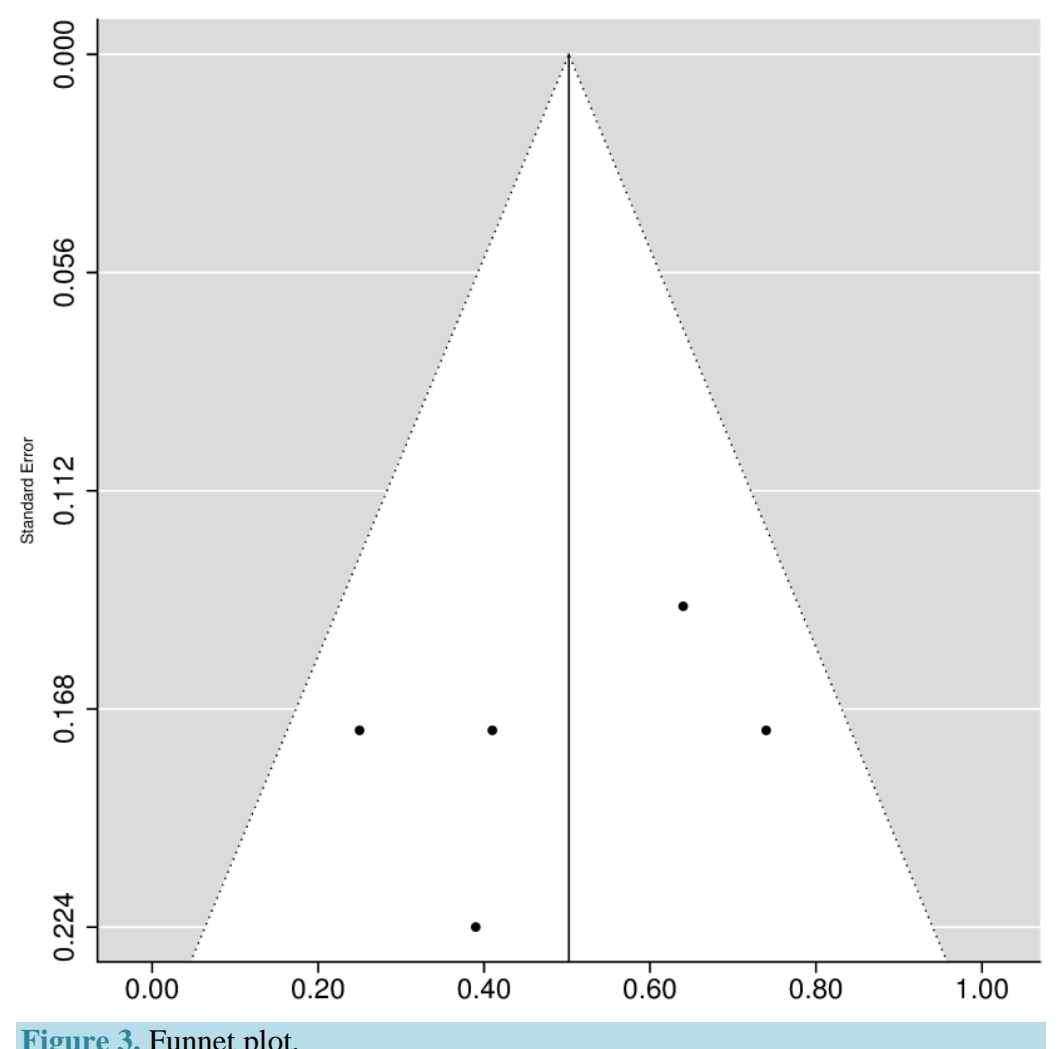

ducing constipation [43]. As compared to placebo, loperamide prolonged significantly the orocaecal transit time (breath hydrogen test after ingestion of lactulose) [44] [45].

At the opposite, RC did not induce a significant change of transit times at the large bowel level as well as at the orocaecal level, as demonstrated by a double-blind cross over study conducted with the therapeutic dose given for one week [6].

The clinical consequences are the significant differences in the constipation frequency, already shown by a review of RC safety [4], and complications frequency linked to this antitransit effect such as ileus [46] toxic megacolon [47]-[49] and colectasia occurring after therapeutic dose of loperamide, which may be facilitated by the concomitant intake of a calcium inhibitor [50] or of a muscle relaxant [51]. As a consequence, in addition to its lack of central nervous effect, RC has a safe profile, not different from placebo and better than loperamide, whatever the patients age [4].

The number of patients involved in the comparison with loperamide, more than 1.6 thousand, was sufficient to point out a significant difference in term of a relatively frequent event, the constipation, but it is obviously too low to establish a difference in term of a rare event such as a complication.

\subsubsection{Implications for Practice and Research}

To help physician to choice an antidiarrhoeal agent, many meta-analysis were published, but almost involved childhood studies. No conclusion can be drawn from the two meta-analyses of an antidiarrhoeal drug with adult patients: one meta-analysis included specific indications but not acute diarrhoea, due to the limited number ( $\mathrm{n}=$ 2) of randomized trials in this indication [52], the other meta-analysis mixed childhood trials $(\mathrm{n}=56)$ and adult trials $(n=7)$ without separated results for adults [53]. Two Cochrane meta-analyses evaluated the efficacy of different oral rehydration solution (ORS): polymer-based ORS was tested versus glucose-based ORS in one meta-analysis [54], but the few trials performed in adults included patients positive for V. cholerae, and in the second meta-analysis, including a majority of adults, the two ORS with different osmolarity were studied in cholera [55].

Thus, up to now, no drug meta-analysis was devoided to adults suffering from acute diarrhoea, except one abstract [16] and a recent student dissertation [56]. 


\subsection{Limitations}

The dose differed between studies and sometimes from the Summary of Product Characteristics (SmPC) dosage. The initial dosing regimen of RC in the first randomized clinical trial performed in adults suffering from acute diarrhoea [35], was: "two capsules at first, followed by one capsule after each unformed stool, with treatment lasting until production of the first formed stool, up to 10 days". This regimen differs from the dosages in the next trials and from recommended dosages in SmPC, but the number of RC capsules ingested, day by day, were very closed to the number of capsules if SmPC dosage was prescribed: $4.3 \pm 2.1$ on day 1 (instead of 4), $2.8 \pm$ 1.9 on day 2 (instead of 3). Overall, they took $10.3 \pm 6.7$ capsules. As patients recovered after $3.4 \pm 0.1$ days of treatment in the RC group (vs. $4.4 \pm 0.1$ in the placebo group), the theorical number of capsules according to SmPC schedule should be between 10 and 11 capsules overall.

Loperamide doses differ from SmPC dose and seem to be not optimized:

During Rogé study [35], loperamide doses (1.33 mg per capsule, two capsules initially, followed by 2 capsules during the next 12 hours, thereafter, one capsule 3 times a day until recovery) seem to be not optimized. But this dosage induced similar efficacy (for instance, time to recovery was $2.2 \pm 0.2$ days in the RC group and $2.3 \pm 0.2$ days in the loperamide group), and significantly worse tolerance as compared to RC group: secondary constipation was significantly more frequent in the loperamide group ( $31.3 \%$ vs. $8.1 \%, p<0.02)$. Duration of bloating lasted significantly longer (1.8 \pm 0 ; 3 days vs. $1.1 \pm 0.2$ days; $p<0.05)$.

Dose during Prado study [40] (2 mg per capsule, 3 times a day until recovery) was also different from SmPC dose, but it induced equivalent efficacy, and significantly worse tolerance as compared to RC group: in terms of associated symptoms, changes from Visits 1 to 2, revealed a significant difference between the two therapeutic groups for abdominal pain $(p=0.024)$ and abdominal distension $(p=0.035)$. For instance, when comparing the two scheduled visits in this study, abdominal pain was still present in $3.0 \%$ of patients treated with RC versus $7.1 \%$ of loperamide patients. Abdominal distension deteriorated in $1.5 \%$ and $4.5 \%$ of patients, respectively. The median duration of abdominal distension was 5.4 hours and 24 hours respectively $(p=0.0001)$. In terms of constipation incidence during the study, there were 74 patients (18\%) in the RC group and 116 patients (29\%) in the loperamide group who had a stool free period lasting 36 hours or more. This difference was statistically significant $(p=0.001)$ between the two treatment groups.

Saccharomyces boulardii was assimilated to a placebo because there is no RCT performed in adults that demonstrated its advantage versus placebo [53].

The definition of constipation was not homogeneous among studies: there is no universal definition of constipation. Miscellaneous definitions were adopted within RCTs, from 48 hours without any stool [39] to a reported adverse event [35] [40]-[42], [Lin Sanren \& Coulden: personal data]. As previously discussed, frequency of antitransit complications are too low to be compared within hundreds of patients.

Pharmacoeconomic evaluation: the diarrhoea reduction is a condition to reduce the period of time the patient has to stop working. But this data was not informed, thus the demonstration of a lower cost is lacking. Anyway the patient social condition was not reported, and an economical approach can not be performed although a pharmacoeconomic analysis was included in one study [42]: its conclusion was a fewer cost in the RC group as compared to the loperamide group.

The meta-analysis from literature collects the largest data as possible and is not limited to study with available individual patient data (IPD), but it can't look for baseline predictors and thus does not allow adjusting with these covariates.

\section{Conclusion}

Compared to placebo, racecadotril is characterized by a clinically relevant earlier remission of diarrhoea. When compared to loperamide, diarrhoea duration was similar, however, significantly fewer secondary constipation adverse effects were observed.

\section{Funding \& Conflict of Interest Statement}

This research received no specific grant from any funding agency in public, commercial or not-for-profit sectors. Authors have declared no competing interests exist. 


\section{References}

[1] Lew, J., Glass, R., Gangarosa, R., Cohen, I., Bern, C. and Moe, C (1991) Diarrheal Deaths in the United States, 1979 through 1987. JAMA, 265, 3280-3284. http://dx.doi.org/10.1001/jama.1991.03460240076031

[2] Garthright, W.E., Archer, D.L. and Kvenberg, J.E. (1988) Estimates of Incidence and Costs of Intestinal Infections Diseases in the United States. Public Health Reports, 103, 107-115. http://www.ncbi.nlm.nih.gov/pmc/articles/PMC1477958/

[3] Baumer, P. and Joulin, Y. (2009) Pre- and Post-Parketing Safety Profiles of Racecadotril Sachets, a "New" Antidiarrhoeal Drug. Journal of Pediatric Gastroenterology and Nutrition, 48, E99.

[4] Baumer, P. and Joulin, Y. (2009) Pre- and Post-Marketing Safety Profiles of Racecadotril Capsules, a "New” Antidiarrhoeal Drug. Gut, 58, A114.

[5] Hinterleitner, T.A., Petritsch, W., Dimsity, G., Berard, H., Lecomte, J.M. and Krejs, G.J. (1997) Acetorphan Prevents Cholera-Toxin Induced Water and Electrolyte Secretion in the Human Jejunum. European Journal of Gastroenterology \& Hepatology, 9, 887-891. http://dx.doi.org/10.1097/00042737-199709000-00012

[6] Bergmann, J.F., Chaussade, S., Coututier, D., Baumer, P., Schwartz, J.C. and Lecomte, J.M. (1992) Effects of Acetorphan, an Antidiarrhoeal Enkephalinase Inhibitor on Oro-Caecal and Colonic Transit Times in Healthy Volunteers. Alimentary Pharmacology \& Therapeutics, 6, 305-313. http://dx.doi.org/10.1111/j.1365-2036.1992.tb00052.x

[7] Lehert, P., Cheron, G., Alvarez Calatayud, G., Cezard, J.P., Gutierrez Castrellon, P., Melendez Garcia, J.M. and Savitha, M.R. (2011) Racecadotril for Childhood Gastroenteritis: An Individual Patient Data Meta-Analysis. Digestive and Liver Disease, 43, 707-713. http://dx.doi.org/10.1016/j.dld.2011.03.001

[8] Higgins, J.P.T. and Green, S. (2011) Cochrane Handbook for Systematic Reviews of Interventions Version 5.1.0. The Cochrane Collaboration. www.cochrane-handbook.org

[9] DerSimonian, R. and Laird, N. (1986) Meta-Analysis in Clinical Trials. Controlled Clinical Trials, 7, 177-188. http://dx.doi.org/10.1016/0197-2456(86)90046-2

[10] Egger, M., Davey Smith, G., Schneider, M. and Minder, C. (1997) Bias in Meta-Analysis Detected by a Simple, Graphical Test. BMJ, 315, 629-634. http://dx.doi.org/10.1136/bmj.315.7109.629

[11] Fleiss, J.L. (1993) The Statistical Basis of Meta-Analysis. Statistical Methods in Medical Research, 2, 121-145. http://dx.doi.org/10.1177/096228029300200202

[12] Higgins, J.P.T., Thompson, S.G., Deeks, J.J. and Altmann, D.G. (2003) Measuring Inconsistency in Meta-Analyses. BMJ, 327, 557-560. http://dx.doi.org/10.1136/bmj.327.7414.557

[13] Light, K.E. (1984) Analyzing Nonlinear Scatchard Plots. Science, 6, 76-78. http://dx.doi.org/10.1126/science.6546323

[14] Stern, J.M. and Simes, R.J (1997) Publication Bias: Evidence of Delayed Publication in a Cohort Study of Clinical Research Projects. BMJ, 13, 640-645. http://dx.doi.org/10.1136/bmj.315.7109.640

[15] Baumer, P., Danquechin-Dorval, E., Bertrand, J., Vetel, J.M., Schwartz, J.C. and Lecomte, J.M. (1992). Action of Acetorphan, an Enkephalinase Inhibitor, in Acute Diarrhea [Action de l'Acétorphan, Inhibiteur de l'Enképhalinase, sur la Diarrhée Aiguë]. Annals of Gastroenterology \& Hepatology, 28, 279-285.

[16] Ang, E.R., Flores, H.H., Estanislao, N.N. and Uy, M. (2009) Efficacy, Tolerability, and Safety of Racecadotril versus Loperamide in Acute Diarrhea among Adults-A Meta-Analysis. UEGW/WCOG, London, 21-25 November, Poster, P0778.

[17] Baldi, F., Bianco, M.A., Nardone, G., Pilotto, A. and Zamparo, E. (2009) Focus on Acute Diarrhoeal Disease. World Journal of Gastroenterology, 15, 3341-3348. http://dx.doi.org/10.3748/wjg.15.3341

[18] Eberlin, M., Mück, T. and Michel, M.C. (2012) Comprehensive Review of the Pharmacodynamics, Pharmacokinetics and Clinical Effects of the Neutral Endopeptidase Inhibitor Racecadotril. Frontiers in Pharmacology, 93, 1-16.

[19] Alam, N.H., Ashraf, H., Khan, W.A., Karim, M.M. and Fuchs, G.J. (2003) Efficacy and Tolerability of Racecadotril in the Treatment of Cholera in Adults: A Double Blind, Randomised, Controlled Clinical Trial. Gut, 52, 1419-1423. http://dx.doi.org/10.1136/gut.52.10.1419

[20] Beaugerie, L., Baumer, P., Chaussade, S., Berard, H., Rozenbaum, W., Pialoux, G., Le Quintrec, Y., Schwartz, J.C. and Lecomte, J.M. (1996) Treatment of Refractory Diarrhoea in AIDS with Acetorphan and Octreotide: A Randomized Crossover Study. European Journal of Gastroenterology \& Hepatology, 8, 485-489.

[21] Baumer, P., Duvivier, C., Berard, H., Pialoux, G., Fretault, N., Rozenbaum, W., Schwartz, J.C. and Lecomte, J.M. (1995) HIV-Related Diarrhea: Efficacy of Acetorphan in a Randomized Controlled Trial. Gastroenterology, 108, A778. http://dx.doi.org/10.1016/0016-5085(95)27421-9

[22] Dorval, E.D., Regimbeau, C., Gamelin, E., Picon, L. and Bérard, H. (1995) Treatment of Acute Chemically Induced Diarrhea by Inhibition of Enkephalinase. Results of a Pilot Study. Gastroentérologie Clinique et Biologique, 19, $27-30$. 
[23] Goncalves, E., Da Costa, L., Abigerges, D. and Armand, J.P. (1995) A New Enkephalinase Inhibitor as an Alternative to Loperamide in the Prevention of Diarrhea Induced by CPT-11. Journal of Clinical Oncology, 13, 2144-2146.

[24] Freyer, G., Rougier, P., Bugat, R., Droz, J.P., Marty, M., Bleiberg, H., Mignard, D., Awad, L., Herait, P., Culine, S., Trillet-Lenoir, V. and CPT-11 F205, F220, F221 and V222 Study Groups (2000) Prognostic Factors for Tumour Response, Progression-Free Survival and Toxicity in Metastatic Colorectal Cancer Patients Given Irinotecan (CPT-11) as Second-Line Chemotherapy after 5FU Failure. British Journal of Cancer, 83, 431-437. http://dx.doi.org/10.1054/bjoc.2000.1303

[25] Ychou, M., Douillard, J.Y., Rougier, P., Adenis, A., Mousseau, M., Dufour, P., Wendling, J.L., Burki, F., Mignard, D. and Marty, M. (2000) Randomized Comparison of Prophylactic Antidiarrheal Treatment versus No Prophylactic Antidiarrheal Treatment in Patients Receiving CPT-11 (Irinotecan) for Advanced 5-FU-Resistant Colorectal Cancer: An Open-Label Multicenter Phase II Study. American Journal of Clinical Oncology, 23, 143-148. http://dx.doi.org/10.1097/00000421-200004000-00008

[26] Saliba, F., Hagipantelli, R., Misset, J.L., Bastian, G., Vassal, G., Bonnay, M., Herait, P., Cote, C., Mahjoubi, M., Mignard, D. and Cvitkovic, E. (1998) Pathophysiology and Terapy of Irinotecan-Induced Delayed-Onset Diarrhea in Patients with Advanced Colorectal Cancer: A Prospective Assessment. Journal of Clinical Oncology, 16, 2745-2751.

[27] Lin, S. (2001) A Multicentric, Randomised, Double-blinded, Comparative, Paralleled Groups Study to Assess the Efficacy and Safety of Domestic Racecadotril 100mg tid po versus Imported Racecadotril 100mg tid po in the Treatment of Acute Diarrhea in Chinese Adults. GSK Report 52607/011.

[28] Gendre, J.P., Baumer, P., Fretault-Heurtebize, N., Schwartz, J.C. and Lecomte, J.M. (1999) Symptomatic Treatment of Adult Acute Diarrhoea: Clinical Equivalence of [R]acetorphan et [R,S]acetorphan. Gastroenterology, 116, G3735.

[29] Coffin, B. and Baumer, P. (2008) Effect of a New Bid Treatment by Racecadotril in Adult Patients with Acute Onset Diarrhea, a Non-Inferiority Study. Gastroenterology, 134, W1046.

[30] Bouhnik, Y., Baumer, P. and Hebuterne, X. (2008) Racecadotril 175 Mg Tablet Bid Is More Efficient than Racecadotril 100mg Capsule tid in the Treatment of Acute Diarrhea in Adults. Gastroenterology, 134, W1044.

[31] Coffin, B., Bouhnik, Y. and Baumer, P. (2008) Efficacy of a New 175 Mg Bid Treatment by Racecadotril in Patients with Acute Diarrhea. Meta-Analysis of 2 Randomized Prospective Studies. Gastroenterology, 134, W1045.

[32] Frexinos, J. and Sallenave, J.R. (1996) Comparison of Loperamide-Oxide and Acetorphan in Acute Diarrhoea. Gut, 39, A173.

[33] Yao, P. and Xi, L. (2011) Clinical Effect of Racecadotril Tablets for Acute Diarrhea in Adults. Chinese Journal of Clinical Pharmacology. http://en.cnki.com.cn/Article_en/CJFDTOTAL-GLYZ201108005.htm

[34] Mehta, S. (2012) A Novel Approach in the Treatment of Acute Infective Diarrhea. Medecine Update, 22, 430-434. http://www.apiindia.org/pdf/medicine_update_2012/gastroenterology_03.pdf

[35] Baumer, P., Danquechin-Dorval, E., Bertrand, J., Vetel, J.M., Schwartz, J.C. and Lecomte, J.M. (1992) Effects of Acetorphan, an Enkephalinase Inhibitor, on Experimental and Acute Diarrhoea. Gut, 33, 753-758. http://dx.doi.org/10.1136/gut.33.6.753

[36] Hamza, H., Ben Khalifa, H., Baumer, P., Berard, H. and Lecomte, J.M. (1999) Racecadotril versus Placebo in the Treatment of Acute Diarrhoea in Adults. Alimentary Pharmacology \& Therapeutics, 13, 15-19. http://dx.doi.org/10.1046/j.1365-2036.1999.00002.x-i1

[37] Moraes, E., Chinzon, D., Coelho, L.G., Fernandes, T.F., Haddad, M.T. and the Brazilian Racecadotril Investigators Research Group. (2001) A Multicentric, Randomised, Investigator-Blind, Parallel Group Study to Assess the Efficacy, Safety and Tolerability of Racecadotril versus Saccharomyces boulardii in the Treatment of Acute Diarrhoea in Adults. [Estudo Multicentrico de Grupos Paralelos, Randomizado, Cego para o Investigator, para Avaliar a Eficacia, Segurança e Tolerabilidade do Racecadotril versus Saccharomyces boulardii no tratamento da diarreia aguda em adultos]. Revista Brasileira de Medicina, 56, 65-74.

[38] Rogé, J., Baumer, P., Berard, H., Schwartz, J.C. and Lecomte, J.M. (1993) The Enkephalinase Inhibitor, Acetorphan, in Acute Diarrhoea: A Double-Blind, Controlled Clinical Trial versus Loperamide. Scandinavian Journal of Gastroenterology, 28, 352-354. http://dx.doi.org/10.3109/00365529309090255

[39] Vetel, J.M., Berard, H., Fretault, N. and Lecomte, J.M. (1999) Comparison of Racecadotril and Loperamide in Adults with Acute Diarrhoea. Alimentary Pharmacology \& Therapeutics, 13, 21-26. http://dx.doi.org/10.1046/j.1365-2036.1999.00003.x-i1

[40] Prado, D. (2002) A Multinational Comparison of Racecadotril and Loperamide in the Treatment of Acute Watery Diarrhoea in Adults. Scandinavian Journal of Gastroenterology, 37, 656-661. http://dx.doi.org/10.1080/00365520212495

[41] Wang, H.H., Shieh, M.J. and Liao, K.F. (2005) A Blind, Randomized Comparison of Racecadotril and Loperamide for Stopping Acute Diarrhea in Adults. World Journal of Gastroenterology, 11, 1540-1543. 
[42] Gallelli, L., Colosimo, M., Tolotta, G.A., Falcone, D., Luberto, L., Curto, L.S., Rende, P., Mazzei, F., Marigliano, N.M., De Sarro, G. and Cucchiara, S. (2010) Prospective Randomized Double-Blind Trial of Racecadotril Compared with Loperamide in Elderly People with Gastroenteritis Living in Nursing Homes. European Journal of Clinical Pharmacology, 66, 137-144. http://dx.doi.org/10.1007/s00228-009-0751-3

[43] Schuermans, V., Vancommel, R., Dom, J. and Brugmans, J. (1974) Loperamide (R 18 553), a Novel Type of Antidiarrhoeal Agent. Placebo-Controlled Comparison of the Constipating Activity and Safety of Loperamide, Diphenoxylate and Codeine in Normal Volunteers. Arzneimittel-Forschung, 24, 1653-1657.

[44] Basilisco, G., Bozzani, A., Camboni, G., Recchia, M., Quatrini, M., Conte, D., Penagini, R. and Bianchi, P.A. (1985) Effect of Loperamide and Naloxone on Mouth-to-Caecum Transit Time Evaluated by Lactulose Hydrogen Breath Test. Gut, 26, 700-703. http://dx.doi.org/10.1136/gut.26.7.700

[45] Sninsky, C.A., Davis, R.H., Clench, M.H., Thomas, K.D. and Mathias, J.R. (1986) Effect of Lidaminine Hydrochloride and Loperamide on Gastric Emptying and Transit of the Small Intestine. A Double-Blind Study. Gastroenterology, 90, 68-73.

[46] World Health Organization (1990) Loperamide. In: The Rational Use of Drugs in the Management of Acute Diarrhoea in Children, WHO, Geneva, 17-22.

[47] Brown, J.W. (1979) Toxic Megacolon Associated with Loperamide Therapy. JAMA, 241, 501-502. http://dx.doi.org/10.1001/jama.1979.03290310041015

[48] Garrett, J.M., Sauer, W.G. and Moertel, C.G. (1967) Colonic Motility in Ulcerative Colitis after Opiate Administration. Gastroenterology, 53, 93-100.

[49] Walley, T. and Milson, D. (1990) Loperamide Related Toxic Megacolon in Clostridium difficile Colitis. Postgraduate Medical Journal, 66, 582-584. http://dx.doi.org/10.1136/pgmj.66.777.582-a

[50] Lelouch, S., Cadranel, J.F., Moussali, J., Benhamou, Y., Gerosa, Y., Gargot, D. and Opolon, P. (1991) Ogilvie’s Syndrome Associated with Treatment by Loperamide and Nifedipine. Gastroentérologie Clinique et Biologique, 15, 455-456.

[51] Petit, R., Bouziane, A., Calès, P., Ruget, O. and Boyer, J. (1993) Toxic Megacolon Caused by Loperamide-Myorelaxants Combination. Gastroentérologie Clinique et Biologique, 17, 62-63.

[52] McFarland, L.V. (2010) Systematic Review and Meta-Analysis of Saccharomyces boulardii in Adult Patients. World Journal of Gastroenterology, 16, 2202-2022. http://www.ncbi.nlm.nih.gov/pmc/articles/PMC2868213/ http://dx.doi.org/10.3748/wjg.v16.i18.2202

[53] Allen, S.J., Martinez, E.G., Gregorio, G.V. and Dans, L.F. (2010) Probiotics for Treating Acute Infectious Diarrhoea. Cochrane Database of Systematic Reviews, 10, Article ID: CD003048.

[54] Gregorio, G.V., Gonzales, M.L., Dans, L.F. and Martinez, E.G. (2009) Polymer-Based Oral Rehydration Solution for Treating Acute Watery Diarrhoea. Cochrane Database of Systematic Reviews, 15, Article ID: CD006519.

[55] Musekiwa, A. and Volmink, J. (2011) Oral Rehydration Salt Solution for Treating Cholera: $\leq 270 \mathrm{mOsm} / \mathrm{L}$ Solutions vs $\geq 310 \mathrm{mOsm} / \mathrm{L}$ Solutions. Cochrane Database of Systematic Reviews, 7, Article ID: CD003754.

[56] Castillo, L.A. (2013) In Adults with Acute Diarrhoea, which Treatment Is More Effective between Loperamide and Racecadotril? PCOM Physician Assistant Studies Student Scholarship, Paper 150.

http://digitalcommons.pcom.edu/pa_systematic_reviews 


\section{Addendum}

\section{A1. A Priori LIST of Requested Information for Each Study}

Investigator: name.

Study centres: number, place (country).

Publication or report reference.

Studied period: dates of first enrolment and last completed.

Objectives.

Methodology: single- or double-blind

Number of patients: planned and analysed.

Diagnosis and main criteria for inclusion.

Test product, dose and mode of administration.

Duration of treatment.

Reference therapy, dose and mode of administration.

Efficacy criteria: including main criterion, secondary criteria and definition of recovery.

Safety: adverses events (AEs), such as secondary constipation.

Statistical methods.

Population included: number of patients, with sexe, age, characteristics of diarrhoea before inclusion (number of stool in the last 24 hrs, diarrhoea duration)

Efficacy results.

Safety results.

Conclusion from publication's or report's author.

\section{A2. Methodological Quality Questionnaire}

\section{Internal validity}

1. Was the assigned treatment adequately concealed prior to allocation?

2. Were the outcomes of patients who withdrew or were excluded after allocation described and included in an intention to treat analysis?

3. Were the outcome assessors blind to assignment status?

4. Were the participants blind to assignment status following allocation?

5. Were the treatment providers blind to assignment status?

6. Were the care programs, other than the trial options, identical?

7. Were the withdrawals $<10 \%$ of the trial population?

\section{External validity}

1. Were the inclusion and exclusion criteria for entry clearly defined?

2. Were the outcome measures used clearly defined?

3. Were accuracy, precision, observer variation of measures adequate?

4. Was the timing of the outcome measures appropriate?

5. The quality of allocation concealment was graded?

\section{Statistical validity}

1. Was the main endpoint mentioned?

2. Was the power analysis described?

4. Statistical technique appropriate? 


\section{A.3. Construction and Calculation of the Methodological Quality Index}

The MQ index was based on the following approach:

(a) a principal components analysis and internal consistency of the original items was performed to assess MQ dimensionality and correlation between items, in particular between internal validity, external validity and statistical characteristics, and assessment of weight of each item;

(b) search of alternative scores based on the dimensionality found in (a);

(c) obtaining the best classification of studies based on MQ items by hierarchical cluster analysis.

(d) the inter-rater variability was tested according a mixed model in testing the significance of the rater random factor for each each dimension. For each item possible responses were: $2=$ adequate, $1=$ unclear, $0=$ inadequate, and undocumented (blank space). Each item was then recoded as a binary value: adequate (1) or not (0 = all responses except for "adequate", thus incorporating previous codes 1 [unclear], 0 [inadequate, and undocumented].

\section{A.4. Individual Results of the Methodology Quality Questionnaire (Recoded Results)}

\begin{tabular}{|c|c|c|c|c|c|c|c|c|c|c|c|c|c|c|c|c|c|c|c|c|c|c|c|}
\hline \multicolumn{3}{|c|}{ Methodology Quality Questionnaire } & \multicolumn{8}{|c|}{ Internal Validity Questions (IV) } & \multicolumn{6}{|c|}{ External Validity Questions (IV) } & \multicolumn{7}{|c|}{ Statistical Validity Questions (SV) } \\
\hline Author(s) & Year & Cont & $\mathrm{X} 1$ & $\mathrm{X} 2$ & X3 & $\mathrm{X} 4$ & $\mathrm{X} 5$ & $\mathrm{X} 6$ & $\mathrm{X} 7$ & IVS* & $\mathrm{X} 8$ & X9 & $\mathrm{X} 10$ & $\mathrm{X} 11$ & $\mathrm{X} 12$ & EVS* & $\mathrm{X} 13$ & $\mathrm{X} 14$ & $\mathrm{X} 15$ & $\mathrm{X} 16$ & $\mathrm{X} 17$ & SVS* & MQS \\
\hline $\begin{array}{l}\text { Vetel JM } \\
\text { (multidose) }\end{array}$ & 1991 & Placebo & 1 & 1 & 0 & 1 & 1 & 1 & 1 & 0.43 & 1 & 0 & 0 & 1 & 0 & 0.20 & 1 & 0 & 1 & 1 & 1 & 0.40 & 0.34 \\
\hline Baumer P & 1992 & Placebo & 1 & 1 & 0 & 1 & 1 & 1 & 1 & 043 & 1 & 0 & 0 & 1 & 0 & 0.20 & 1 & 0 & 1 & 1 & 1 & 0.40 & 0.34 \\
\hline Rogé & 1993 & Loperan & 1 & 0 & 0 & 1 & 1 & 1 & 1 & 0.36 & 1 & 0 & 0 & 0 & 0 & 0.10 & 0 & 0 & 0 & 1 & 1 & 0.20 & 0.22 \\
\hline Frexinox J & 1996 & $\begin{array}{l}\text { Loperamide } \\
\text { oxide }\end{array}$ & 1 & 0 & 0 & 1 & 1 & 1 & 0 & 0.29 & 1 & 0 & 0 & 1 & 0 & 0.20 & 0 & 0 & 0 & 0 & 0 & 0.00 & 0.16 \\
\hline Hamza H & 1999 & Place & 1 & 0 & 0 & 1 & 1 & 1 & 1 & 0.36 & 1 & 1 & 1 & 1 & 0 & 0.40 & 1 & 1 & 0 & 1 & 1 & 0.40 & 0.39 \\
\hline Vetel JM & 1999 & Lope & 1 & 0 & 0 & 1 & 1 & 1 & 1 & 0.36 & 1 & 1 & 1 & 1 & 0 & 0.40 & 1 & 1 & 1 & 1 & 1 & 0.50 & 0.42 \\
\hline Lin Sanren & 2000 & Lopera & 0 & 1 & 0 & 0 & 0 & 1 & 1 & 0.21 & 1 & 1 & 1 & 1 & 0 & 0.40 & 1 & 0 & 0 & 0 & 1 & 0.20 & 0.27 \\
\hline Coulden S & 2001 & Lope & 0 & 0 & 0 & 0 & 0 & 1 & 1 & 0.14 & 1 & 1 & 1 & 1 & 0 & 0.40 & 1 & 0 & 0 & 1 & 1 & 0.30 & 0.28 \\
\hline Moraes E & 2001 & $\begin{array}{l}\text { Saccharomyces } \\
\text { boulardii }\end{array}$ & 0 & 0 & 0 & 0 & 0 & 1 & 0 & 0.07 & 1 & 1 & 1 & 1 & 0 & 0.40 & 1 & 1 & 1 & 1 & 1 & 0.50 & 0.32 \\
\hline Prado D & 2002 & Loperamide & 0 & 0 & 0 & 0 & 0 & 1 & 1 & 0.14 & 1 & 1 & 1 & 1 & 0 & 0.40 & 1 & 1 & 1 & 1 & 1 & 0.50 & 0.35 \\
\hline Wang $\mathrm{HH}$ & 2005 & Loperamide & 0 & 1 & 0 & 0 & 0 & 1 & 1 & 0.21 & 1 & 1 & 1 & 1 & 0 & 0.40 & 1 & 0 & 0 & 1 & 1 & 0.30 & 0.30 \\
\hline Coffin B & 2007 & $\begin{array}{l}\text { Dexecadotril } \\
\text { Placebo }\end{array}$ & 1 & 1 & 0 & 1 & 1 & 1 & 1 & 0.43 & 1 & 1 & 1 & 1 & 0 & 0.40 & 1 & 1 & 1 & 0 & 1 & 0.40 & 0.41 \\
\hline Gallelli L & 2010 & Loperamide & 0 & 0 & 0 & 1 & 0 & 1 & 0 & 0.14 & 1 & 1 & 1 & 1 & 0 & 0.40 & 1 & 0 & 1 & 1 & 0 & 0.30 & 0.28 \\
\hline Yаo P & 2011 & $\begin{array}{l}\text { Oral } \\
\text { rehydration } \\
\text { solution }\end{array}$ & 0 & 0 & 0 & 0 & 0 & 2 & ? & 4 & 0 & 0 & 0 & 0 & 0 & 0 & 0 & 0 & 0 & 0 & 0 & .00 & 0.05 \\
\hline \multirow[t]{3}{*}{ Mehta S } & 2012 & $\begin{array}{l}\text { Placebo } \\
\text { octreotide }\end{array}$ & 0 & 0 & 0 & 0 & 0 & 1 & 1 & 0.14 & 0 & 0 & 1 & 1 & 0 & 0.20 & 0 & 0 & 1 & 1 & 1 & 0.30 & 0.21 \\
\hline & & Mean & 0.47 & 0.33 & 0.00 & 0.53 & 0.47 & 1.07 & 0.73 & 0.26 & 0.87 & 0.60 & 0.67 & 0.87 & 0.00 & 0.30 & 0.73 & 0.33 & 0.53 & 0.73 & 0.80 & 0.31 & 0.29 \\
\hline & & SD & 0.5 & 0.47 & 0 & 0.50 & 0.50 & 0.25 & 0.41 & 0.12 & 0.34 & 0.49 & 0.47 & 0.34 & 0 & 0.13 & 0.44 & 0.47 & 0.50 & 0.44 & 0.40 & 0.15 & 0.10 \\
\hline
\end{tabular}

\section{A.5. Statistical Addendum}

Meta-analyses on survival technique, can be done in first calculating the HR o for each study to save the HR and its SE in a file HR. MTM and MTP require for each study the mesure Yi and its variance Vari (thus not forget to calculate Vari $=$ sei*sei in case where the SE is found). When only two variables are provided, MTM and MTP will consider these variables as Yi and Vari in the order.

The values Yi and Vari must sometimes be transformed: for proportions (thus calculation of RR, HR, etc.), the log transformed values must be provided for Yi and Vari. Thus in the MTP command you must request/ transf = exp. This is also true if you use MTM on log-transformed data.

Finally, this particular use with two variables can be used for a meta-analysis on one data: for instance, calculating the pooled value of a percentage, a market share, etc. over several studies.

Conversion Techniques

The compared studies may have been analyzed following various techniques: 
0) The main endpoint of the study must be used even it is not the DD. In this case, an equivalence will be searched through a calibration with DD, through IPD techniques, and the CI will be corrected according to the correlation. If several endpoints are used, the arithmetic mean of the converted values will be used.

1) If Cox proportional Hazard was used, results are provided in terms of HR or $\log (\mathrm{HR})$. However, values can also be provided as medians. An approximation assuming exponential models is that as in this model $\mathrm{S}(\mathrm{t})=$ $\exp (-\mathrm{ht})$, thus the median is such that $0.5=\exp (-\mathrm{ht})$, thus med $=\ln (2) / \mathrm{h}$, thus the median is inversely related with hazard $h$, and when knowing the medians $m_{s}$ and $m_{r}$, the value $\mathrm{mr} / \mathrm{ms}=\mathrm{hs} / \mathrm{hr}=\mathrm{HR}$.

2) It is also possible to convert Logrank values into HR. assuming that $Z=(\mathrm{O}-\mathrm{E}) / \mathrm{V}$ where $\mathrm{O}, \mathrm{E}$ and $\mathrm{V}$ are the sum of the observed, expected and variance of the difference O-E, HR can be found as Log (HR) $=\mathrm{Z}$ sqrt( $4 / \mathrm{nd})$ where nd $=$ total number of events in both groups. Because $Z^{2}$ is provided instead of $Z$ (in the case of $R$ command Survival ), the value sqrt $\left(\mathrm{Z}^{2}\right)$ must be first calculated, thus the sign of $\mathrm{Z}$ is unknown, thus when $\mathrm{HR}$ is found, if expect $\mathrm{HR}<1$ is expected, $1 / \mathrm{HR}$ will be used.

3) Indirect equivalence from another endpoint. In some studies Stool Output was provided as the main endpoint. The relationship between SO and DD was calculated through a calibration $\log (\mathrm{DD})=\mathrm{k} 0+\mathrm{k} 1 \log (\mathrm{SO})$. The significance of $\mathrm{k} 0$ and $\mathrm{k} 1$ were calculated. The conversion from SO into DD was calculated as HR = Exp(k0 $+\mathrm{k} 1 \log (\mathrm{SO}) \mathrm{t} / \mathrm{k} 0+\mathrm{k} 1 \log (\mathrm{SO}) \mathrm{r})$.

4) Calculating $\operatorname{Var}(\mathrm{HR})$ is possible, still under assumption of exponential distribution. As $S(t)=\exp (\mathrm{ht})$, for each exponential curve corresponding to the two treatments, assuming that Median or Mean $\mu$ and variance $\sigma 2$, it is known from exponential distribution that $\mu=1 / \mathrm{h}$ and $\mathrm{var}=1 / \mathrm{h}^{2}$. As $\mathrm{HR}=\mathrm{hs} / \mathrm{hr}$ we can calculate the SE(HS) through SE $(\log (\mathrm{HS}))=\log (\mathrm{hs})-\log (\mathrm{hr})$. If $\sigma(\mathrm{hs})=\sigma$, $\operatorname{var}(\log (\mathrm{hs}))=\operatorname{var}(\mathrm{hs})|\log (\mathrm{m})|$ where $\log ()$ is the derivative of $\log ()$ at point $\mathrm{m}$, thus $1 / \mathrm{hs}$ in this case. $=>\operatorname{Var}(\log (\mathrm{hs}))=\operatorname{var}(\mathrm{hs}) /(1 / \mathrm{ms})=\left(1 / \mathrm{ms}^{2}\right) /(1 / \mathrm{ms})=1 / \mathrm{ms}$, further more the SE of var(hs) is $1 / \mathrm{ms} \cdot 1 \sqrt{(\mathrm{ns})}$. It follows that SE $(\log (\mathrm{HS}))=\sqrt{1 /(\mathrm{ms} \cdot \mathrm{ns})+1(\mathrm{mr} . \mathrm{nr})}$.

\section{A6. Prisma Flow Diagram}

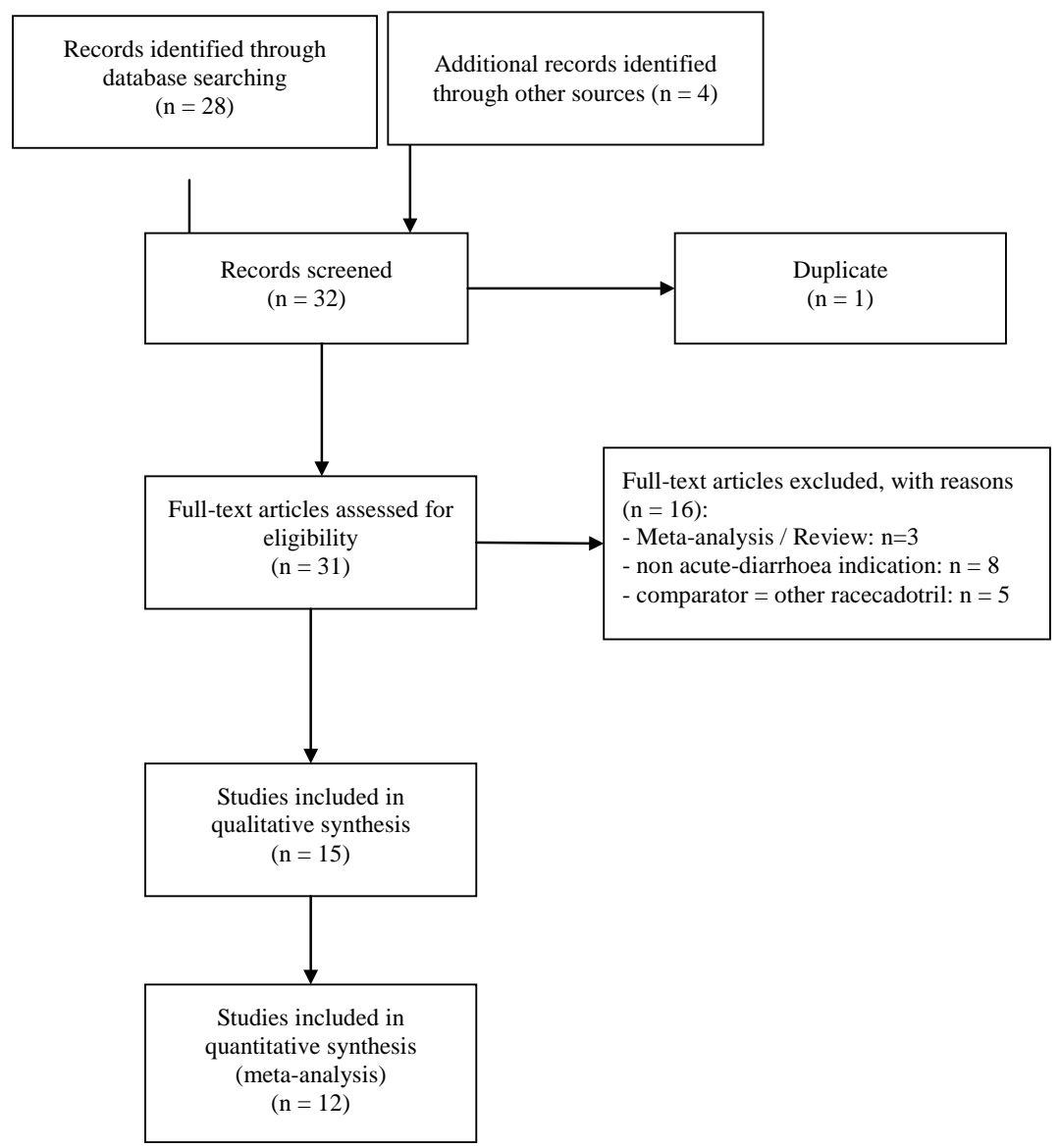

